\title{
Comparative Analysis and Path Study of Global Value Chains Between China and International Countries -- Based on CiteSpace Knowledge Graph Analysis
}

\author{
$\mathrm{Na} \mathrm{Xu}{ }^{1}$, Hongyan Liang ${ }^{2 *}$, and Junchen $\mathrm{Mu}^{3}$ \\ ${ }^{123}$ College of Economics and Management, Tianjin University of Science and Technology, 29 13th Street, Tianjin \\ Economic and Technological Development Zone, Tianjin, China \\ * Corresponding author:lhy09208@163.com
}

\begin{abstract}
This paper uses CiteSpace V software to sort out and analyze the research literature on GVCs published in CSSCI and Web of Science database from 1998 to 2019 and compares the international research with the Chinese research. The similarities and differences are deeply explored between the two sides in the research basis, research hotspots, development trends, and research forces of GVCs. The main findings are as follows : (1) The international focus is mainly on sustainable development and environmental impact, while China, an economy in transition, pays more attention to its international division of labor and industrial upgrading; (2) The research on GVC in China started late, the domestic cooperation network is relatively loose, and the domestic resource integration is not strong enough; (3) China faces international and domestic pressures in the promotion of the global value chain, and the requirement of sustainable development also increases the challenge for efficient and clean development; (4) China acquires the leading role in the restructuring of the global value chain and strives to improve its position in the global value chain by constructing a step-by-step cooperation model of "global value chain -- domestic value chain -- regional value chain -- global value chain".
\end{abstract}

Keywords: Global value chain, CiteSpace, sustainable development, industrial upgrading, refactoring, the Belt and Road, the path.

\section{INTRODUCTION}

The global value chain was formed in the process of industrial transfer in developed countries in the last century. Due to the pressure of rising costs of labor, land, and environmental pollution control, developed countries transfer labor-intensive industries (such as textiles) and environmentally polluting industries (such as papermaking) and other production links at the bottom of the value chain to developing countries (such as China, India, and Southeast Asian countries), and the high-value-added design and $R \& D$ links are kept in their own countries. If China wants to break the technological barriers of developed countries, it must promote technological innovation and reform, and promote the industrial chain to move from the low end to the high-end links with high added value. With the rapid development of emerging industries such as big data, mechanical automation, artificial intelligence, and the decline and weakening of traditional manufacturing, emerging economies are gradually changing the pattern of global trade, and the world's industrial pattern is undergoing a major reshuffle. How to succeed in a new industry? "Overtaking on a curve" is the primary issue facing China's economic transformation.

How is China's progress in global value chain research, how is it different from foreign research, and what are the directions for its efforts to integrate abroad? How does China explore the upgrade path of the global value chain, what is the future development trend, and whether China's development path can be used as a reference for developing countries to upgrade the global value chain. There is no systematic understanding. However, a clear understanding of domestic and foreign research plays an important role in clarifying the direction of domestic efforts and enhancing the status of the global value chain. This paper uses CiteSpaceV software to visually analyze the 
research on global value chains at home and abroad, combing and analyzing the research foundation, research hotspots, development trends, and research strengths of global value chains, and discusses the similarities and differences between China's global value chain research and international research, to sort out the motivation and path of China's participation in the restructuring of global value chains, as well as the future direction of international research efforts, and provide some suggestions for developing countries that are also seeking national transformation and development in the world.

\section{DATA SOURCE AND RESEARCH PROCESS}

\subsection{Research tools and data sources}

To more intuitively, systematically and comprehensively observe the research history, current situation and future trends in the field of global value chains at home and abroad, this article uses the CiteSpace V visual analysis software (version 5.7.R1) developed by Professor Chaomei Chen of Drexel University to do Knowledge graph analysis of related documents in the GVC field. The data in this article are selected from authoritative databases at home and abroad. Foreign data are selected from the core collection in the Web of Science database, and domestic data are selected from the Chinese Social Science Citation Index (CSSCI) database. Foreign countries use "global value chain" as the subject and domestic "global value chain" as keywords. The search time is July 4, 2020, and the time span is from 1998 to 2019. Invalid documents such as news reports and duplicate documents were eliminated. There are 3,311 foreign documents and 1,267 domestic documents.

\subsection{Overall analysis}

As shown in Fig. 1, from 1998 to 2019, the number of Chinese and Foreign papers has shown an overall upward trend year by year, indicating that the popularity of the global value chain has continued to rise, and there is still a high degree of discussion. Related documents in the WOS database first appeared in 1994, and the first global value chain document in the CSSCI database was published in 2003, indicating that China's research in this field started relatively late. Among them, the volume of China's CSSCI publications in 2015 rose sharply by $91.18 \%$ compared with 2014 . This is closely related to China's two policies that year. "The Vision and Actions of the Silk Road Economic Belt and the 21st Century Maritime Silk Road", the other is "Developing a higher level of open economy, actively participate in global economic governance and the supply of public products, to enhance our country's institutional voice in global economic governance." The second policy was proposed at the Fifth Plenary Session of the 18th Central Committee.

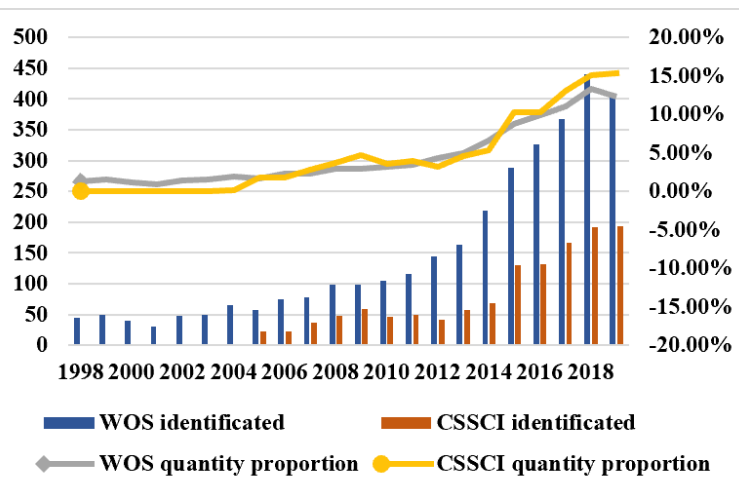

Fig. 1. Research trends at home and abroad Source: CSSCI and web of science.

\section{THE THEORETICAL BASIS AND FRONTIER HOTSPOTS OF GLOBAL VALUE CHAIN}

\subsection{The theoretical basis and research content of $G V C$}

Research on global value chain originated from Comparative Advantage (1985) written by Professor Michael Porter [2] of Harvard Business School in the 1980s, in which the concept of the value chain was first put forward, holding that all enterprises are a kind of aggregation. The aggregate consists of basic activities such as research and development, production, sales, and logistics, as well as auxiliary activities such as raw material supply, human resources, and finance. These activities create value and form an interrelated relationship chain, which is the origin of the internal value chain of an enterprise. In addition, the company is still in an external environment, affected by the external environment, and effectively integrates with raw materials, technology, labor, and other input links, and then assembles these links to form commodities, and finally completes the process of value circulation through market transactions and consumption. The spatial allocation of these links depends on the comparative advantages of various countries and regions. Compared with Michael Porter's theory of single firm value-added, Bruce Kogut's theoretical research reflects the relationship between vertical separation of the value chain and global spatial reallocation Therefore, although Michael Porter's theory of value chain is more popular, Bruce Kogut's theory has played a more far-reaching role in the development of GVC theory. Since entering the 21 st century, more and more scholars have begun to pay attention to this field, and many excellent documents have been produced. Then, it further elaborates the research contents of GVCs at home and abroad through the cluster analysis of CiteSpace. 


\subsubsection{Study abroad}

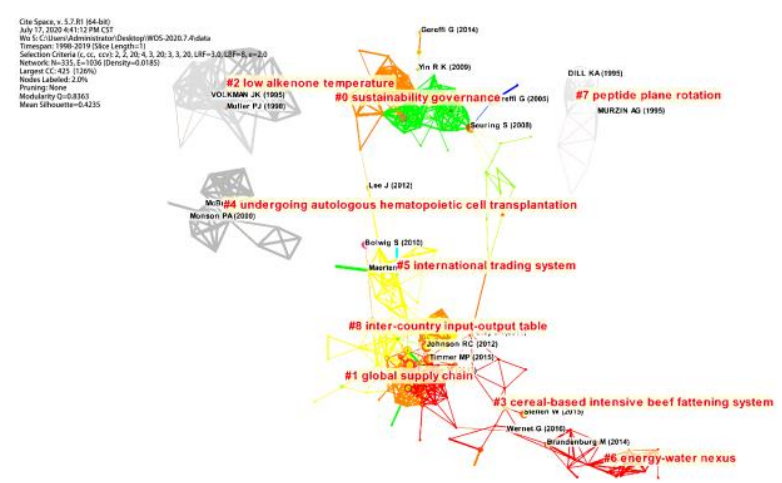

Fig. 2. Foreign literature cited clustering analysis

After de-duplication of the literature retrieved from the core collection database of Web of Science, a total of 2804 literature was screened out. Then, the data was imported into CiteSpace, "Node types" were selected to select "Reference" (literature co-cited), and the clustering name extracted from the topic was selected. LLR (maximum likelihood) clustering method was used for clustering, and the clustering graph was shown in Fig. 2.

As shown in Fig. 2, the clustering results have 9 directions, and there are 5 clusters related to the topic, respectively \#0 sustainable management, including 43 kinds of literature. \#1 Global supply chain, including 42 papers; \#5 international trading system, including 18 papers; \#6 energy-water nexus, including 16 kinds of literature; \#8 inter-country input-output table, including 14 kinds of literature. Professor Chaomei Chen [3] believes that the literature with strong Burst intensity produced by Burst detection has a major milestone significance in the development of this field. Therefore, this paper will find out the key literature through the function of Burstness in the software and focus on the research topic by combining the literature with high citation frequency.

A total of 21 citations were detected abruptly. Through reading the literature, it can be concluded that foreign research contents mainly include the following aspects: (1) governance research; (2) sustainable development research; (3) research on industrial upgrading; (4) agricultural development research.

Governance research: Scholars are committed to building a complete global value chain governance framework. The most typical governance structure is the driven governance proposed by Gereffi [4], including production-driven and buyer-driven. In 2005, Gereffi, Humphrey and Sturgeon [5] did further research and finally formed five types of governance: market relationship-led value chain, modular value chain, relationship value chain, capture value chain, and hierarchical value chain.

Sustainable development research: Seuring and Muller [6] found that although the research in the field of sustainable supply chain focuses on environmental issues, the integrated research on environment, society and sustainable development is still insufficient. Peter, Minx, Weber, et al. [7] and Lenzen, Moran, and Kanemoto [8] have found that international trade poses an environmental threat to developing countries and will exacerbate the threat of biodiversity in developing countries. As can be seen. Under economic globalization, the status of developing countries in the division of labor in the global value chain has an adverse impact on their sustainable development.

Research on industrial upgrading: Giuliani, Pietrobelli, and Rabellotti [9] provided great help. From a micro perspective, they found that the key to industrial upgrading is the organizational model of inter-firm linkages and the governance of the value chain. At the same time, it is found that the degree of accumulation of knowledge, as well as the adaptability, degree of codification and complexity of the knowledge base affect the ability and method of enterprise upgrading.

Agricultural development research: The research in this area mainly focuses on the impact of the reorganization of the agricultural supply chain triggered by participation in international trade on agricultural development and the interests of small farmers. Reardon, Barrett, Julio, et al. [10] and Maertens, Swinnen [11] found that smallholders can participate in global value chains through modern markets. Laborintensive production systems and the high standards of international trade can increase rural incomes and reduce poverty.

\subsubsection{Domestic research}

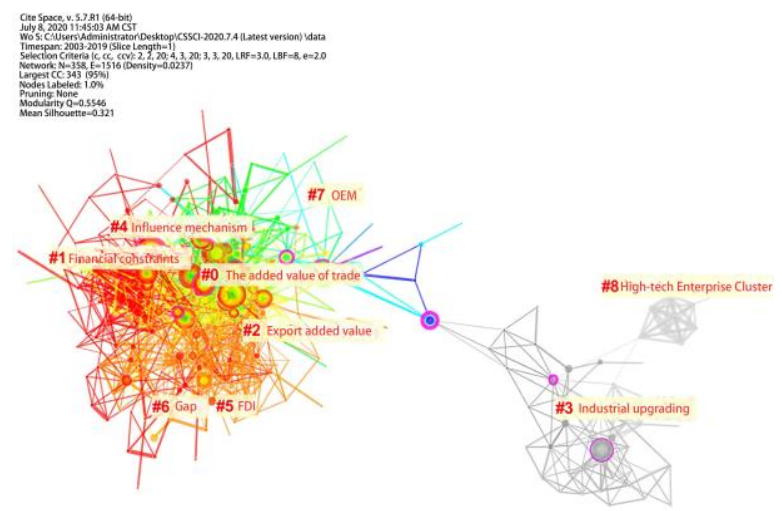

Fig. 3. Domestic literature was cited clustering results

Using the same method to get the domestic cluster map Fig. 3. 
As shown in Fig. 3, the clustering results have 9 directions, respectively \#0 The added value of trade, including 72 kinds of literature. \#1 Financial constraints, including 51 papers; \#2 Export added value, including 43 literatures; \#3 Industrial upgrading, including 42 papers; \#4 Influence mechanism, including 40 literatures; \#5 FDI, including 38 literatures; \#6 gap, including 31 literatures; \#7 OEM, including 17 literatures; \#8 High-tech Enterprise Cluster, including 9 papers.

There are 23 citations detected abruptly, and one third of which are foreign documents, it is concluded that the domestic research content mainly includes the following aspects: (1) Research on industrial upgrading; (2) International Trade Research; (3) Governance research; (4) Research on overflow effect; (5) Status research.

Research on industrial upgrading: Chinese domestic scholars are committed to exploring the path of industrial development and industrial upgrading. Hui Zhang [12] [13] believes that countries should strive to integrate into their own value-added links, and choose appropriate industrial cluster upgrade models according to the different layout of value links. He [14] believes that the driving forces of global value chains are mainly producers, buyers and blenders. China should formulate corporate and regional development strategies based on the dynamic mechanism of global value chains. Zhibiao Liu and Jie Zhang [15] proposed an upgrade path from GVC to NVC to promote China's industrial upgrading. Bin Liu, Qian Wei, Yue Lu et al. [16] found that from a micro perspective, the servitization of the manufacturing industry has a clear promotion effect on the participation of Chinese companies in the global value chain.

International trade research: A number of scholars have found that compared with traditional trade statistics methods, calculating international trade based on value-added statistics is more accurate [17, 18]. China's international trade is dominated by laborintensive products, but processing trade and FDI have caused certain negative effects on the sustainable development of China's economy [19]. However, Maoqing Fan and Wei Huang [20] found that China's participation in international production activities has become increasingly complex. In import and export trade, the contribution of labor-intensive industries to domestic value added is declining, while the contribution of the knowledge-intensive manufacturing and service industries export is increasing rapidly, and the proportion of GVC is higher than that of capitalintensive.

Governance research: The research on governance of global value chains is mostly derived from foreign experience, and there are few key domestic documents in this field.
Research on overflow effect: Feng Tao and Shitian Li [21] found that traditional GVC participation forms, such as domestic OEM companies, have a significant impact on knowledge spillover and learning effects due to factors such as learning tendency, knowledge complexity, and trust between manufacturers. It is easier to integrate into the global value chain by adopting the technological innovation method of "introduction, digestion, absorption, and re-innovation. However, Jie Zhang and Wenping Zheng [22] found through empirical research that exports did not have a significant impact on the innovation activities of Chinese local enterprises. This situation is particularly significant in cooperation with developed countries, and it is prominent in private enterprises.

Status research: Most scholars have found that China is still in a low position in the international division of labor, especially in high-tech industries [24, 25].

To sum up, due to the differences in international and domestic development plans, development stages and development goals, the research contents of GVC in China and abroad are very different. The research contents of China mainly revolve around "Is it beneficial to participate in GVC or international division of labor? Which GVCs value nodes should you participate in? What is the complexity of industries participating in the international division of labor? How to get out of the low end of GVCs? How to achieve industrial transformation and upgrading for sustainable development?" and so on. Based on global value chain governance and industrial upgrading, more attention has been paid to sustainable development and agricultural development, as well as ecology and small-scale peasant economy.

\subsection{Research hotspots and evolution trends of global value chains}

\subsubsection{Research hotspots}

Keyword co-occurrence map helps us to analyze research hotspots and their evolution [27]. Therefore, we select Node Types as Keyword and pruning the data using a Minimum Spanning Tree algorithm. Select Static Cluster to Show Cluster View-static /Show Merged Network for all time ranges. Finally, the cooccurrence knowledge map of domestic and foreign high-frequency keywords in the study of the global value chain $(\mathrm{GVC})$ is drawn, to explore its research hotspots and evolution trend. 


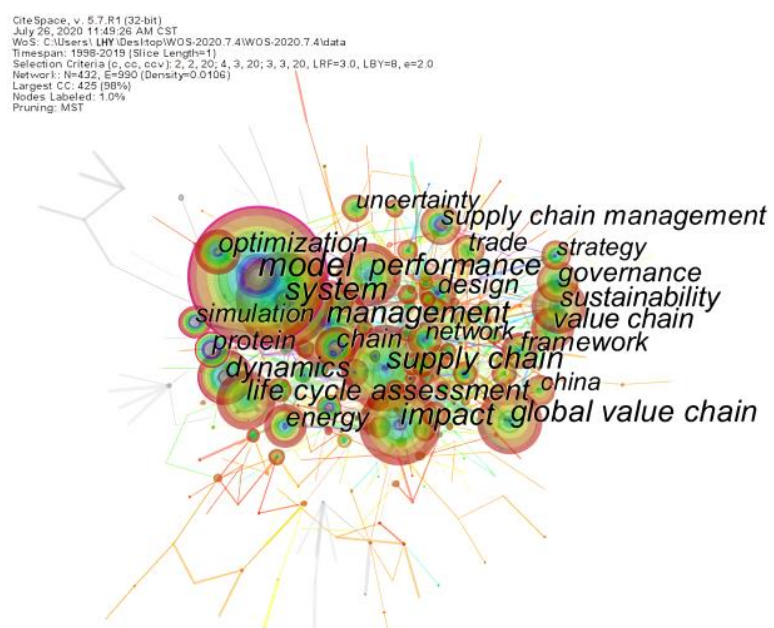

Fig. 4. Foreign keyword co-occurrence graph

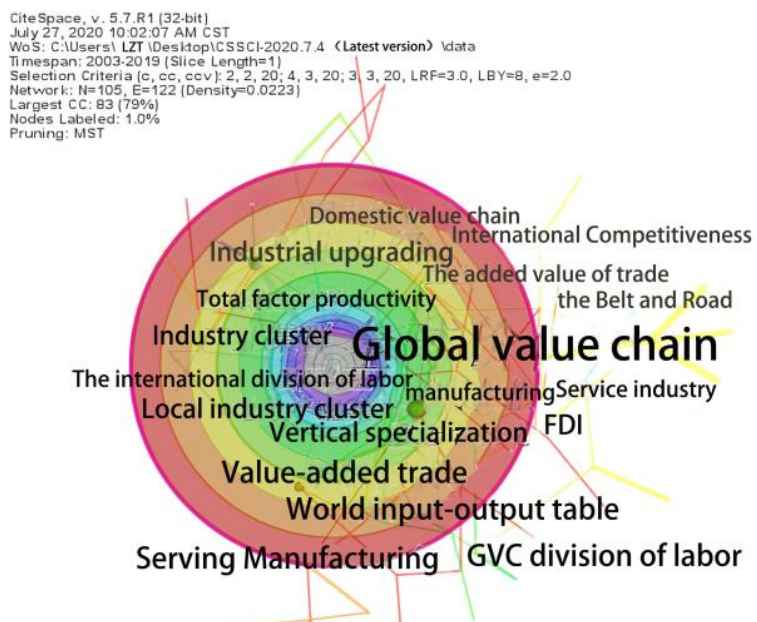

Fig. 5. Domestic keyword co-occurrence graph

The color change from a cool blue tone to a warm red tone indicates a time change from morning to night. The size of the node reflects the frequency of the keyword. The larger the circle, the higher the frequency, indicating that the keyword's attention is higher, and the number of documents studying this direction is also greater. Nodes with high betweenness centrality values tend to identify cross-border potentials that may lead to transformative discoveries [26]. Table 1 is sorted by betweenness centrality and lists the most frequent hot keywords at home and abroad.

Table 1. Statistical table of hot keywords at home and abroad

\begin{tabular}{cccc}
\hline Frequency & keywords & Centrality & Time \\
\hline 224 & model & 0.23 & 1998 \\
157 & system & 0.09 & 2002 \\
140 & management & 0.07 & 2002 \\
135 & supply chain & 0.06 & 2008 \\
129 & impact & 0.04 & 2008 \\
104 & global value chain & 0.07 & 2011 \\
103 & performance & 0.06 & 2011
\end{tabular}

\begin{tabular}{cccc}
95 & $\begin{array}{c}\text { life cycle } \\
\text { assessment }\end{array}$ & 0.02 & 2010 \\
94 & dynamics & 0.13 & 1998 \\
87 & sustainability & 0.03 & 2012 \\
\hline 91 & Industrial upgrading & 0.22 & 2004 \\
60 & manufacturing & 0.18 & 2015 \\
48 & Added value trade & 0.15 & 2014 \\
38 & Industry cluster & 0.11 & 2005 \\
30 & Value-added to & 0.24 & 2015 \\
23 & trade & 0.06 & 2017 \\
22 & the Belt and Road & 0.13 & 2015 \\
21 & WIOT & 0.09 & 2006 \\
20 & Division of GVC & 0.1 & 2015 \\
& Vertical \\
specialization & & \\
\hline
\end{tabular}

\subsubsection{Evolutionary trends}

We can get a sense of the evolution trend of hot research through the time zone chart. In the keyword, time zone diagram, the vertical corresponding time of each keyword is the time when the keyword first appeared. The larger the node, the higher the frequency of its occurrence, and the more growth rings, the wider the time zone of its influence.

It can be seen from time zone Fig. 6 and Fig. 7 that the evolution and development of foreign GVC research hotspots can be divided into three stages. The first stage, 1998-2005: the growth period, the hot words during this period are mainly GVC model, system, management, optimization, etc. The second stage, 20062015: the outbreak period, during which the hot words are mainly supply chain, impact, governance, performance life cycle assessment, etc.; The third stage, 2016-present: sustained growth period, during which the hot words are mainly sustainable development, coordination, etc. As you can see, the research focus has gradually shifted from "model", "management", "life cycle assessment" and "performance" to "sustainability", "international trade" and "environmental" Impact.

Compared with foreign studies, the first paper on GVC was published in China in 2003, and it can be divided into three evolutionary stages from 2003 to now. The first stage, 2003-2004: the embryonic stage, research hot topics around industrial clusters and industrial upgrading; The second stage, 2005-2013: growth period, the hot words during this period are mainly global value chain division, the international division of labor, domestic value chain, etc. The third stage, from 2014 to now: the outbreak period. Research hotspots in this stage focus on value-added trade, manufacturing, the Belt and Road, Sino-US trade, restructuring, and other aspects. It can be seen that the focus of China's GVC research frontier is gradually developing from "industrial upgrading" and "GVC division of labor" to "added value in trade", "the Belt 
and Road", "Sino-US trade", "service industry", "GVC position", and "restructuring" of GVC.

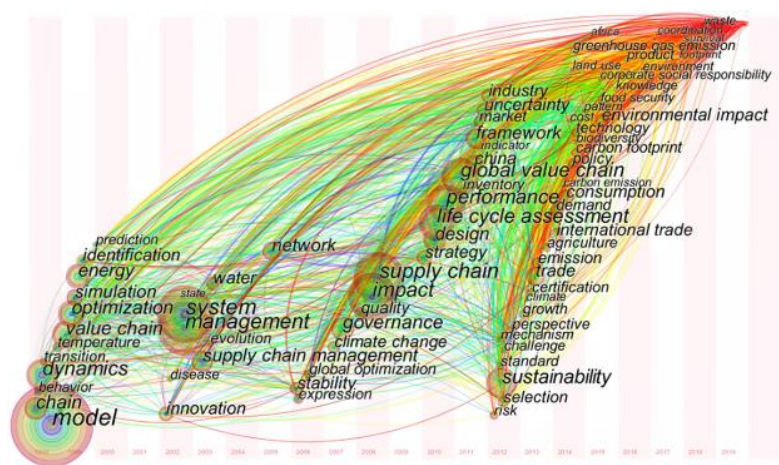

Fig. 6. Trends in the evolution of foreign hot keywords

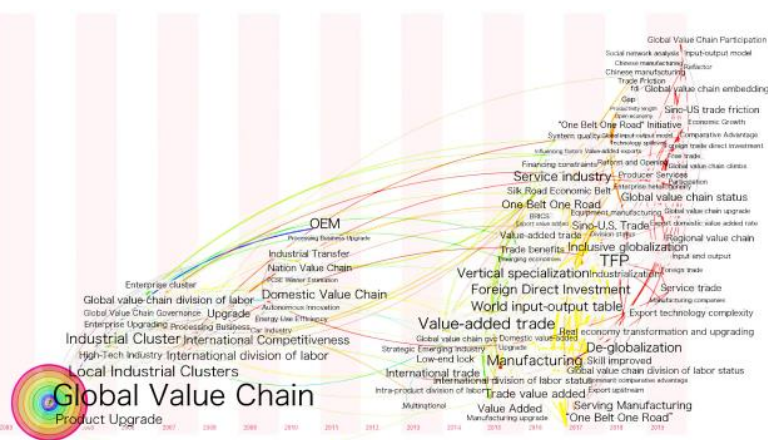

Fig.7. Trends in the evolution of domestic hot keywords

\section{GLOBAL VALUE CHAIN INSTITUTIONAL COOPERATION NETWORK}

The collaboration graph can reveal the social relations among scholars, countries, and research institutions in a certain research field, to evaluate their academic influence [27]. Therefore, we chose "Node Types" as "Institution" and combined it with the "Burst Terms" function to draw the cooperation graph in Fig. $8 \& 9$. The line represents the cooperative relationship between institutions, and the thickness of the line represents the strength of cooperation. Some nodes, with a high mediating centrality (at least 0.1 ), are highlighted in purple circles.

From Table 2 and Figures $8 \& 9$, it can be seen that domestic institutions have greater international discourse power in global value chain research, such as Chinese Acad Sci and Tsinghua Univ, and have relatively close ties with foreign institutions. However, with domestic institutions, there is less communication, and the overall domestic network is relatively sparse. There is almost no obvious cooperation network among major research institutions. The blockage of information flow is likely to cause a large domestic information collection cost in China, thereby causing a waste of national resources.
Table 2. Distribution of research institutions in the global value chain area

\begin{tabular}{|c|c|c|c|}
\hline $\begin{array}{l}\text { Number } \\
\text { of posts }\end{array}$ & Institution & Centrality & Date \\
\hline 38 & Chinese Acad Sci & 0.12 & 2003 \\
\hline 33 & Wageningen Univ & 0.11 & 2010 \\
\hline 24 & Univ Sao Paulo & 0.08 & 2012 \\
\hline 23 & Tsinghua Univ & 0.08 & 2009 \\
\hline 21 & Cornell Univ & 0.05 & 1999 \\
\hline 17 & Imperial College London & 0.04 & 2003 \\
\hline 17 & Univ British Columbia & 0.03 & 2003 \\
\hline 10 & Nanjing University & 0 & 2009 \\
\hline 10 & $\begin{array}{c}\text { Institute of World } \\
\text { Economics and Politics }\end{array}$ & 0 & 2015 \\
\hline 8 & $\begin{array}{l}\text { Institute of Financial } \\
\text { Strategy }\end{array}$ & 0.01 & 2016 \\
\hline 7 & $\begin{array}{l}\text { Institute of Asia-Pacific } \\
\text { and Global Strategy }\end{array}$ & 0 & 2014 \\
\hline 6 & $\begin{array}{c}\text { Institute of Financial } \\
\text { Strategy, }\end{array}$ & 0 & 2016 \\
\hline
\end{tabular}

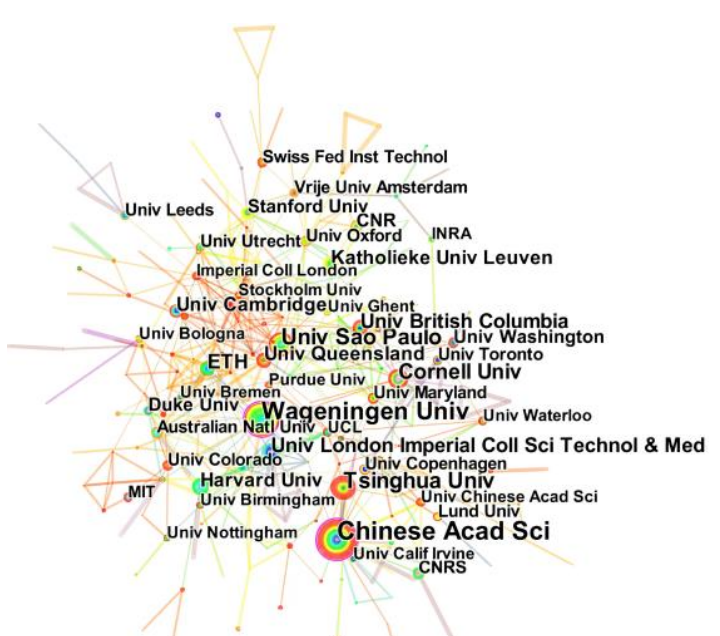

Fig. 8. A map of cooperation between foreign institutions 


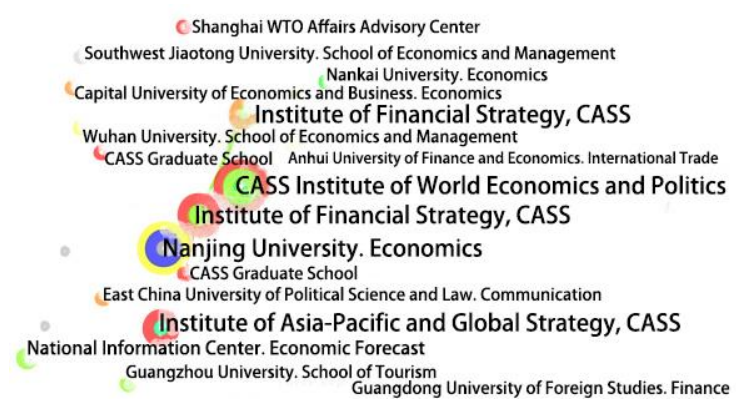

Fig. 9. A map of cooperation between domestic institutions

\section{CONCLUSION}

This paper uses CiteSpace software to analyze the research literature on GVCs published in CSSCI and Web of Science database from 1998 to 2019 and draws the following conclusions:

First, the intuitive conclusions drawn from the knowledge map: (1) In terms of research content, foreign research mainly focuses on governance, sustainable development, industrial upgrading, and agricultural development research, while domestic research mainly focuses on industrial upgrading, international trade, overflow effect, and the research on the status of global value chains; (2) The research on global value chains is both extensive and detailed, continuously integrating into the new themes of the times; (3) Global value chain research still has a high degree of popularity, and future trends abroad are more inclined to sustainable development. Domestic institutions are more inclined to restructure the global value chain; (4) Research institutions are mostly scientific research institutes. Compared with foreign research, the cooperation network of domestic institutions is evacuated and the cooperation is not close;

Second, the motivation and path of China's participation in the restructuring of global value chains derived from the comparative analysis of knowledge graphs: (1) The main reasons for the restructuring are as follows: one is to be in line with international standards and to comply with the sustainable development requirements of the times; the other is to deal with manufacturing reflux measures of developed countries and the international trade friction; the third is to enhance the status of international division of labor and independent innovation capabilities. (2) On the road to restructuring, China has made the following efforts: one is the exploration from global value chain to domestic value chain and regional value chain; the other is from traditional industry to manufacturing service, digital creative industry, and service trade. The third is the exploration from the foundry to the "the Belt and Road" initiative, equipment manufacturing cooperation, and international production capacity cooperation. In future research, China will pay more attention to the development of knowledge-intensive industries and the impact of service trade.

Through the above findings, we can also make the following suggestions for the further development of China and other developing countries of the same type: first, China should continue to deepen capacity cooperation with "the Belt and Road" countries and actively build a bilateral and multilateral trading system. According to the factor endowments and development needs of the cooperating countries, constructing a regional value chain cooperation network in a targeted and segmented manner; second, China should actively respond to international initiatives, and future research should be combined with sustainable development; third, to drive development with innovation, strengthening independent innovation construction, and enhancing the country's core competitiveness; fourth, strengthening the awareness of intellectual property protection, and increasing the country's motivation for independent innovation; fifth, continuing to strengthen cooperation with the division of labor and cooperation in developed countries, reasonably deploying overseas investment in high-tech fields, and strengthening the sharing and docking of cutting-edge technologies, core talents and high-quality resources with developed countries; sixth, paying attention to the research cooperation between domestic institutions of higher learning and scientific research institutes, to share resources, and integrate talents; seventh, to create an excellent business environment and foreign investment environment, and actively guide multinational companies to invest in high-tech and high-value-added industries.

Although the research has given general conclusions and recommendations, the political, economic, and social systems of developing countries are different, and there are also large differences in the characteristics of infrastructure and resource endowments. China's research history and development path can only be used as a general reference. It is necessary to formulate more specific measures based on national conditions.

\section{ACKNOWLEDGMENT}

The study was supported by the Ministry of Education Humanities and Social Sciences Planning Fund project: International Capacity Cooperation Domain Governance Research (17YJAGJW005) based on the Global Value Chain.

\section{REFERENCES}

[1] B. Kogut. Designing Global Strategies. Comparative and Competitive Value-Added Chains. SMR, 26(1): 15-28 (1985). 
[2] Michael, E., Porter. Competitive advantage: creating and sustaining superior performance. NY: FP (1985).

[3] C. Chen. Science Mapping: A Systematic Review of the Literature. JDIS 2(02):1-40 (2017).

[4] Gereffi, G. \& Korzeniewicz, M. (Eds.). Commodity chains and global capitalism. Westport, CT: Praeger (1994).

[5] G. Gereffi, J. Humphrey, T. Sturgeon. The Governance of Global Value Chains. RIP, 12(1) (2005).

[6] S. Seuring, M. Müller. From a literature review to a conceptual framework for sustainable supply chain management. JCP, 16(15) (2008).

[7] Peters Glen, P., Minx Jan, C., Weber Christopher, L., Edenhofer Ottmar. Proceedings of NAS of US, 108(21): 8903-8908 (2011).

[8] Lenzen, M., Moran, D., Kanemoto, K., et al. International trade drives biodiversity threats in developing nations. Nature, 486(7401):109-112 (2012).

[9] Giuliani, E., Pietrobelli, C., Rabellotti, R. Upgrading in Global Value Chains: Lessons from Latin American Clusters. WD, 33(4):549-573 (2004).

[10]Reardon, T., Barrett, C.B., Julio, A., Berdegué, et al. Agrifood Industry Transformation and Small Farmers in Developing Countries. WD, 37(11):1717-1727 (2009).

[11]M. Miet, S. Johan, F.M. Trade, Standards, and Poverty. Evidence from Senegal. WD, 37(1). 161178 (2009).

[12]H. Zhang. Global Value Chain Theory and my country's Industrial Development Research. CIE, (05): 38-46 (2004).

[13]H. Zhang. Research on the upgrading model of local industrial clusters under the global value chain. CIE, (09): 11-18 (2005).

[14]H. Zhang. Global value chain dynamic mechanism and industrial development strategy. CIE, (01): 4048 (2006).

[15]Z. Liu, J. Zhang. From integrating into the global value chain to constructing national value chain: strategic thinking of China's industrial upgrading. AM, (09):59-68 (2009).

[16]B. Liu, Q. Wei, Y. Lu, K. Zhu. Serving Manufacturing and Value Chain Upgrading. EP, 51(03): 151-162 (2019).
[17]Z. Liu, X. Chen, C. Yang, Leonard, K., Cheng, K. C. Zhang. Non-competitive Input-OccupiedOutput Model and Its Application: A Perspective of Sino-US Trade Surplus. CSS, (05):91-103+206207 (2007).

[18]L. Wang. Value-added trade in the context of global value chain division of labor: framework, measurement and application. ER, (03): 150-160 (2013).

[19]J. Zhang, Z. Chen, Y. Liu. The measurement and change mechanism of China's export domestic value-added. ER, 48(10): 124-137 (2013)

[20]M. Fan, W. Huang. Research on the evolution of China's trade industry structure based on the decomposition of global value chains. WE, 37(02): 50-70 (2014)

[21]F. Tao, S. Li. Product development knowledge spillovers and learning effects in the global value chain foundry process: An empirical study based on Dongguan's electronic information manufacturing industry. MW, (01): 115-122 (2008).

[22]J. Zhang, W. Zheng. The innovation effect of Chinese local enterprises in the global value chain. ER, 52(03): 151-165 (2017).

[23]H. Tang, H. Zhang. International division of labor within products and the promotion of value chains in developing countries. ER, 44(09): 81-93 (2009).

[24]X. Huang, G. Yang. Research on the international division of labor status of China's high-tech industries: a transnational analysis based on a noncompetitive input-occupancy-output model. WE, 33(05): 82-100 (2010).

[25]L. Liu. Measurement and analysis of China's participation in global value chains: Based on the investigation of value-added trade.WER, (06): 71 $83+128$ (2015).

[26]Chen, C., Chen, Y., Horowitz, M., et al. Towards an explanatory and computational theory of scientific discovery.JI, 3(3):191-209 (2009).

[27]Y. Chen, C. Chen, Z. Liu, Z. Hu, X. Wang. The methodological function of CiteSpace knowledge graph. SSS, 33(02):242-253 (2015). 